\title{
Methane quashes green credentials of hydropower
}

At the time, it must have sounded like a sensible case of sustainable development. During the 1980s, about 2,500 square kilometres of Amazonian rainforest was flooded to create the Balbina dam to feed the energy demands of the Brazilian city of Manaus. A sizeable chunk of rainforest was lost, but Brazil gained access to a non-polluting energy source. It's a compromise Brazil has made many times; more than $80 \%$ of the country's domestic electricity is generated by hydropower plants.

Yet the clean, green image of dams may have been seriously overstated. Researchers are gathering in Paris next week to discuss greenhouse-gas emissions from tropical reservoirs.

"If these estimates are correct, figures for annual global methane emissions need to be increased by a fifth." Some of the latest findings point to a disturbing conclusion: that the global-warming impact of hydropower plants can often outweigh that of comparable fossil-fuel power stations. If that's correct, current energy strategies, particularly in developing nations, will need to be rethought.

The problem lies with the organic matter in the reservoir. Large amounts are trapped when land is flooded to create the dam, and more is flushed in after that. In the warm water of tropical dams, this matter decays to form methane and carbon dioxide. Although both are greenhouse gases, the main worry is methane, which has more than 20 times the warming impact of carbon dioxide over a 100-year period. In the specific case of Balbina, there is now a rough consensus: in terms of avoiding greenhouse-gas emissions, a fossil-fuel plant would have been better.

But that is where the agreement ends. On one side of the debate is Philip Fearnside, a conservation biologist at the National Institute for Research in the Amazon in Manaus. His work, based mainly on theoretical calculations, looks at water leaving dams. Many dams release water from several metres below the surface, so the flow goes through an abrupt pressure change. Fearnside calculates that this causes methane release, much as carbon dioxide fizzes out when carbonated drinks are opened. His latest results suggest that a typical tropical hydropower plant will, during the first ten years of its life, emit four times as much carbon as a comparable fossil-fuel station.

Lining up against him in a decade-long dispute are Luiz Pinguelli Rosa and his colleagues at the Federal University of Rio de Janeiro, who accuse Fearnside of exaggerating reservoir emissions. They complain in particular that

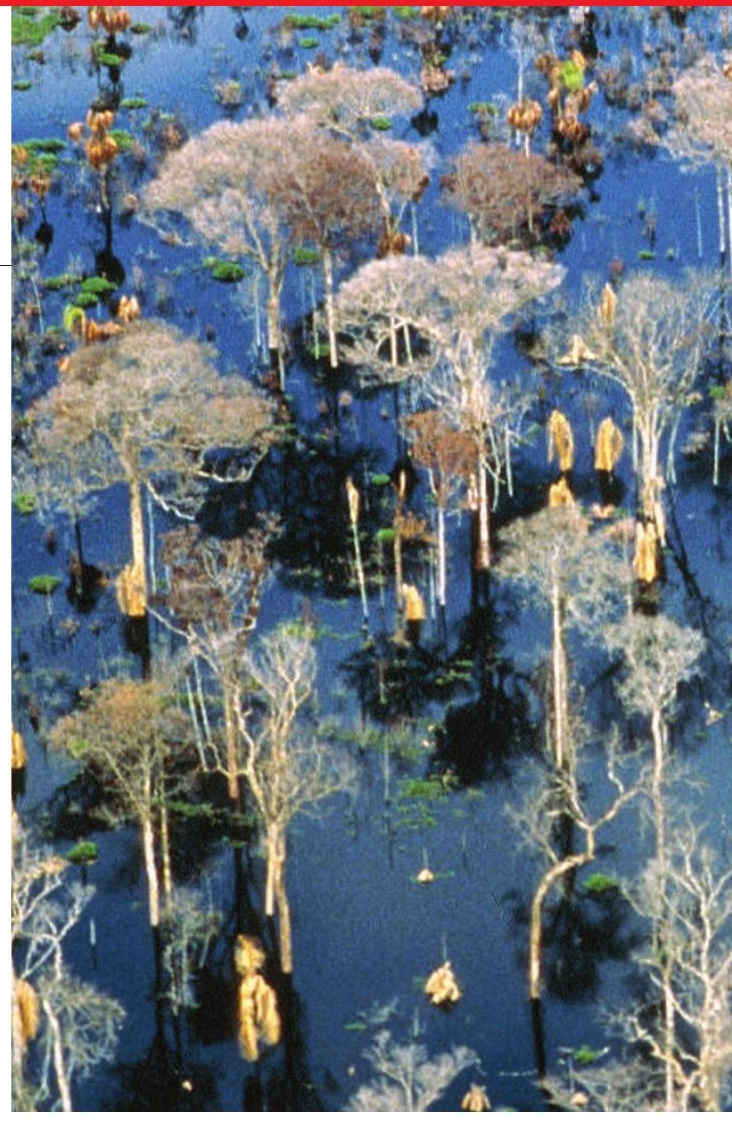

Fearnside has extrapolated from measurements taken on the Petit Saut dam in French Guiana; the data were taken in the years immediately after the reservoir was created, when the store of organic matter would have been greatest.

With few data sets available on tropical dams, the debate has increased in acrimony without approaching a conclusion. Environmental groups question the impartiality of Rosa's work, which is funded in part by the hydropower industry. Rosa strongly denies any bias, and in turn accuses Fearnside of seeking to show that "something is wrong with dams".

The Paris meeting, which runs on 5-6 December and is organized by the United Nations

\section{Preprint analysis quantifies scientific plagiarism}

How often do researchers plagiarize each other's work? The question has previously been almost impossible to answer, as no large-scale survey of the practice had been conducted. But a computer scientist has now examined more than a quarter of a million documents from a physics preprint server. The results contain the comforting news that blatant deception is rare, but suggest that minor acts of misconduct may be more common than was previously thought.

Student plagiarism can often be checked using specialist databases of essays available for sale online, but plagiarism in published research is harder to police. Many publishers don't allow search engines to index the full text of their papers, so it's impossible to run electronic checks on new studies. Those small surveys that have been done revealed little evidence of plagiarism, but suggested that duplicate publications - in which a significant amount of an existing paper by the same author is reused without providing a reference to the original - could make up about $10 \%$ of the literature in some fields (see Nature 435, 258-259; 2005).

Firmer numbers can now be put on those estimates, thanks to the work of Daria Sorokina, a PhD student at Cornell University in Ithaca, New York. Sorokina's software trawled more than 280,000 entries in arXiv, a database of mainly physics, maths and computer-science preprints maintained at Cornell. Her code divides documents into seven-word chunks and looks for pairs of papers that share a suspicious number of such chunks (common phrases such as "this work was supported in part by" are excluded). The result is a list of possible plagiarisms or, if the documents share a common author, duplicate publications.
The search turned up 677 examples of possible plagiarism, of which Sorokina and her colleagues took a close look at 20. Only four were innocent mistakes, such as articles that quoted text from a third scientist. Three of the others were judged to be 'serious plagiarism' in which one article was essentially a copy of another, and in the others, parts of the paper such as the introduction or related work sections had been copied without appropriate references being given. If the analysis scales up, then just $0.2 \%$ of arXiv documents contain plagiarism. The results will be presented at the 


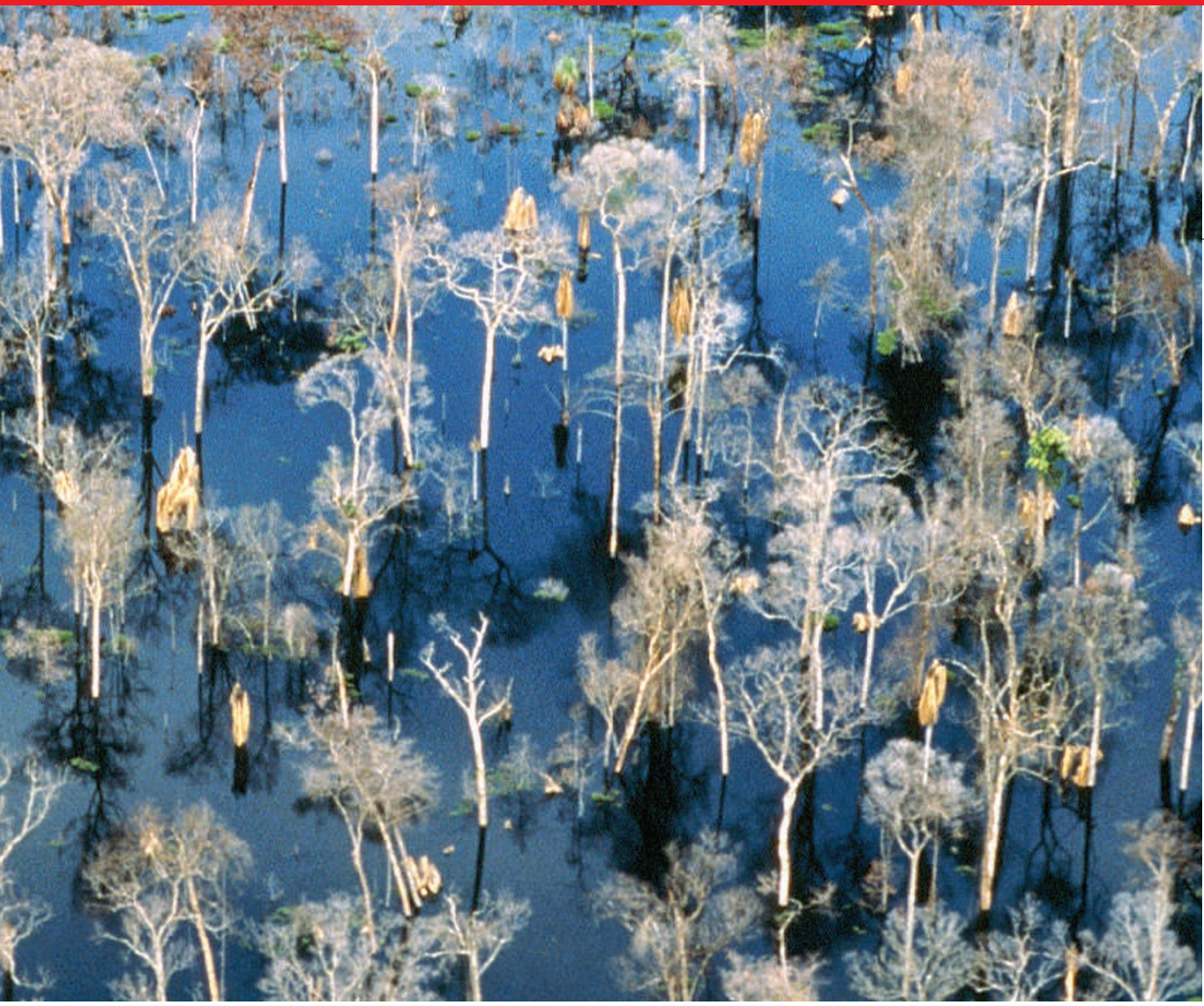

The greenhouse-gas emissions from regions flooded by dams may have been grossly underestimated.
Educational, Scientific and Cultural Organization (UNESCO), is unlikely to settle their dispute, but researchers will discuss new methane data. On 14 November, for example, Frédéric Guérin of the Laboratory of Meteorology in Toulouse, France, and his colleagues published results on methane release from sites downstream of three tropical dams ${ }^{1}$. They found that so much methane builds up in the dam that downstream emissions, which are rarely factored into estimates of a reservoir's impact, should account for between a tenth and a third of total emissions. Another new paper estimates that, for Balbina, downstream emissions alone have the same greenhouse warming potential as $6 \%$ of all the fossil fuels consumed by São Paulo, a city of more than 11 million people ${ }^{2}$.

Even without these downstream emissions, the global impact of dams may be significant. Danny Cullenward, an energy-policy expert at Stanford University, has made preliminary calculations of the impact of Fearnside's findings. Cullenward stresses that more data are needed, but his estimates suggest that dams release between 95 million and 122 million tonnes of methane per year. If correct, estimates of annual

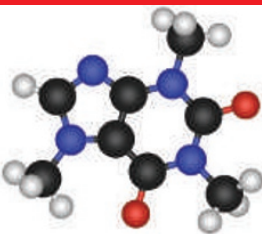

MATERIALS RESEARCH

SOCIETY

Get the latest news from

the Boston meeting.

http://blogs.nature.

com/news/blog global methane emissions (which do not generally include dam emissions) need to be increased by a fifth. Even extrapolating Rosa's figures gives Cullenward a total of 23 million tonnes.

Many think enough is known to start acting now. Some worry about the huge dam projects tentatively planned for tropical areas, such as a $\$ 5$-billion project on the Congo river. Another concern is the Clean Development Mechanism (CDM), a system that allows developed nations to fund clean-energy projects in developing nations in return for credits that can be used to meet Kyoto Protocol targets. Current rules allow certain hydropower projects to be funded under the CDM, a situation some scientists and environmental groups would like to see revised.

But matters are unlikely to change without more data, so researchers at the UNESCO meeting will discuss which questions to prioritize and how best to work together. More substantial progress could begin in 2008, when the Intergovernmental Panel on Climate Change (IPCC) will decide whether or not to start work on a special report on renewable energy. Previous IPCC special reports have had significant political impact, and the dams question is likely to fit very well into the scope of the proposed energy study, says Bert Metz, a climate-policy expert at the Netherlands Environmental Assessment Agency and co-chair of one of the IPCC's three working groups. Jim Giles

1. Guérin, F. et al. Geophys. Res. Lett. 33, L21407 (2006).
2. Kemenes, A., Forsberg, B. R. \& Melack, J. M. in Proc. 8th Int.
Conf. Southern Hemisphere Meteorology and Oceanography,
Foz do Iguaçu, Brazil, 24-28 April 2006, 663-668 (INPE, São José dos Campos, Brazil, 2006).
IEEE International Conference on Data Mining, to be held on 18-22 December in Hong Kong.

Results for duplicates are potentially more alarming but harder to assess. Sorokina identified 30,316 pairs where one was largely a copy of the other - more than $10 \%$ of the database. But arXiv differs from journals in that researchers submit conference proceedings as well as the journal papers that are derived from them. Paul Ginsparg, a Cornell physicist who worked with Sorokina on the survey, says the "vast majority" of duplicates found are of this type, but adds that he was surprised at the number of student theses that included material copied verbatim from other sources.
Despite the leap forward provided by the arXiv survey, many issues remain unresolved. The survey picks up only cases where the source that has been plagiarized

"This may be the most accurate global estimate that we have for plagiarism in the scientific literature."

is also present on the arXiv database (although in many fields arXiv has near-complete coverage). And the software is unable to pick up 'intelligent plagiarism', where material copied from another author is reworded.

Researchers may also behave differently when submitting to arXiv compared with peer-reviewed journals, and different rates may exist for biologists, who rarely use preprint servers. Plagiarism in biology could in principle be studied using PubMed Central, an archive of journal papers maintained by the US National Institutes of Health. Ginsparg says he has discussed this with PubMed's staff, but such a survey would currently be of limited use, as only a small fraction of papers are placed in the database after publication.

Larry Claxton, a toxicologist at the US Environmental Protection Agency in North Carolina, who has studied plagiarism in the life sciences, says he would like to see a more detailed examination of the duplicates in the arXiv study before interpreting the results. But despite the limitations, he says, "this may be the most accurate global estimate that we have for plagiarism in the scientific literature".

Ginsparg says he would now like arXiv to scan all new entries using Sorokina's software and alert the author in the case of suspicious overlap. The researcher would then have the option of rewriting the paper or, if they felt the overlap was justified, submitting as usual. Ginsparg says the system could be in place by the middle of next year. Preliminary discussions have also taken place with CrossRef, a publishers' group, about whether journals could work together to implement a similar scheme. Jim Giles 